\title{
ANALISIS FAKTOR - FAKTOR YANG MEMPENGARUHI PERSALINAN SEKSIO SESARIA DI RSUD TARAKAN, KALIMANTAN UTARA
}

\section{ANALYSIS OF FACTORS - FACTORS AFFECTING CHILDBIRTH OF SEKSIO SESARIA AT TARAKAN HOSPITAL, NORTH KALIMANTAN}

\author{
Ika Yulianti' ${ }^{1}$, Ririn Ariyanti'2), Rahmi Padlilah ${ }^{3)}$ \\ 1),2),3) Fakultas Kesehatan, Universitas Borneo Tarakan \\ Email: ${ }^{1}$ ikatamaevan@gmail.com
}

\begin{abstract}
ABSTRAK
Insiden persalinan seksio sesaria meningkat dibandingkan persalinan normal. Penelitian bertujuan untuk menganalisis faktor-faktor yang mempengaruhi persalinan seksio sesaria. Jenis penelitian adalah studi penelitian analitik observasional dengan pendekatan kasus control yang dilaksanakan di RSUD Tarakan tahun 2020. Sampel dipilih secara purposive sampling sebanyak 200 subjek penelitian. Persalinan seksio sesaria dipengaruhi oleh umur $<20$ dan $\geq 35$ tahun $(\mathrm{OR}=1.78 ; 95 \% \mathrm{CI}=2.53-13.79 ; \mathrm{p}<0.001)$, paritas yang multipara $(\mathrm{OR}=1.81 ; 95 \% \mathrm{CI}=2.36-15.94 ; \mathrm{p}<0.001)$, riwayat penyakit $(\mathrm{OR}=1.61$; $95 \% \mathrm{CI}=2.04-12.17 ; \mathrm{p}<0.001)$, faktor risiko $(\mathrm{OR}=1.36 ; 95 \% \mathrm{CI}=1.53-9.92 ; \mathrm{p}=$ $0.004)$, indikasi medis $(\mathrm{OR}=2.04 ; 95 \% \mathrm{CI}=3.09-19.19 ; \mathrm{p}<0.001)$ dan gambaran ANC yang lengkap $(\mathrm{OR}=-1.89 ; 95 \% \mathrm{CI}=2.76-15.50 ; \mathrm{p}<0.001)$. Hal ini dapat disimpulkan bahwa persalinan seksio sesaria dipengaruhi oleh umur $<20$ dan $\geq 35$ tahun, paritas yang multipara, memiliki riwayat penyakit, memiliki faktor risiko, ada indikasi medis dan gambaran ANC yang lengkap.
\end{abstract}

\section{Kata Kunci: Determinan Faktor, Persalinan Seksio Sesaria, Indikasi Medis}

\begin{abstract}
The incidence of seksio sesaria labor increased compared to normal childbirth. The research aims to analyze the factors that influence childbirth. This type of research is an observational analytical research study with a case control approach conducted at Tarakan Hospital in 2020. The sample was selected purposively sampling as many as 200 research subjects. Seksio sesaria childbirth is influenced by the ages of $<20$ and $\geq 35$ years $(O R=1.78 ; 95 \% C I=2.53-13.79 ; p<0.001)$, multipara parity $(O R=1.81 ; 95 \% C I=2.36$ - 15.94; $p<0.001)$, disease history $(O R=1.61 ; 95 \% C I=2.04-12.17 ; p<0.001)$, risk factors $(O R=1.36 ; 95 \% C I=1.53-9.92 ; p=0.004)$, medical indication $(O R=2.04 ; 95 \%$ $C I=3.09-19.19 ; p<0.001)$ and a complete ANC overview $(O R=-1.89 ; 95 \% C I=2.76-$ $15.50 ; p<0.001$ ). It can be concluded that seksio sesaria childbirth is influenced by the age of $<20$ and $\geq 35$ years, parity is multipara, has a history of disease, has risk factors, there are medical indications and a complete anc picture.
\end{abstract}

Keywords: Determinant Factor, Childbirth Seksio Sesaria, Medical Indications 


\section{PENDAHULUAN}

Persalinan seksio sesaria adalah tindakan yang dilakukan untuk mengurangi adanya komplikasi obstetri pada masa persalinan dengan indikasi tertentu. Prevalensi seksio sesaria secara global terus meningkat seiring dengan keadaan sosial ekonomi masyarakat yang meningkat (Manyeh et al., 2018). WHO (2015) mengusulkan bahwa prevalensi persalinan seksio sesaria sebaiknya kurang dari $15 \%$ dibandingkan dengan jumlah persalinan secara keseluruhan. Persalinan seksio sesaria memiliki risiko tinggi untuk ibu dan juga janin dalam kandungan, namun demikian angka persalinan seksio sesaria terus meningkat di banyak negara termasuk Indonesia. Prevalensi persalinan seksio sesaria di Indonesia dari tahun 19862012 mengalami peningkatan yang signifikan yaitu dari $2 \%$ menjadi $22 \%$ (Nababan et al., 2018).

Persalinan seksio sesaria menyebabkan dampak yang negatif terkait meningkatnya biaya layanan kesehatan, risiko morbiditas dan mortalitas ibu perinatal. Riwayat persalinan seksio sesaria pada persalinan sebelumnya dihubungkan dengan terjadinya kelahiran bayi dengan berat badan rendah dan prematur dengan gangguan pernapasan dan neurologis serta tingginya insiden infeksi pada ibu postpartum (Benzouina et al., 2016). Angka morbiditas dan mortalitas persalinan seksio sesaria lebih tinggi dibandingkan dengan persalinan pervaginam. Hasil studi menunjukkan bahwa angka prevalensi morbiditas terjadi pada 116 kasus dari 2.933.457 persalinan seksio sesaria (Sobhy et al., 2019). Evaluasi yang komprehensif terkait data faktor-faktor yang mempengaruhi komplikasi pada persalinan seksio sesaria yang ada diperlukan untuk menetapkan tindakan yang tepat untuk mencegah AKI dan AKB setelah persalinan dengan seksio sesaria serta untuk merencanakan program dan mengalokasikan sumber daya untuk persalinan seksio sesaria yang aman (Kaeg et al., 2018; Knight et al., 2015). Hasil penelitian yang dilakukan di Indonesia, India dan Filipina menunjukkan bahwa fasilitas kesehatan berperan penting dalam penurunan risiko komplikasi persalinan seksio sesaria sehingga perlu deteksi dini pasien dengan indikasi persalinan seksio sesaria pada masa kehamilan dan persalinan serta ibu dianjurkan bersalin di rumah sakit. Diperlukan pedoman atau standar pelayanan yang komprehensif baik di tingkat provinsi atau Negara (Sepehri et al., 2017).

Determinan kompleks persalinan seksio sesaria, seperti karakteristik pasien, ketersediaan teknologi dan sumber daya kesehatan berpengaruh terhadap persalinan dengan seksio sesaria (Betran et al., 2016). Oliveira et al. (2016) menjelaskan bahwa faktor yang berhubungan dengan persalinan seksio sesaria adalah riwayat persalinan SC, kelebihan berat badan/obesitas, pendapatan keluarga per kapita dan komorbiditas. Banyak faktor yang telah memberikan kontribusi terhadap meningkatnya persalinan seksio sesaria termasuk faktor medis dan non-medis sehingga perlu mendapatkan perhatian dan penelitian terkait faktor yang berpengaruh terhadap persalinan seksio sesaria untuk menurunkan persalinan seksio sesaria (de Oliveira et al., 2016). Berdasarkan latar belakang permasalahan tersebut peneliti tertarik untuk menganalisis faktor yang mempengaruhi persalinan seksio sesaria di RSUD Tarakan.

\section{METODE PENELITIAN Desain Penelitian}

Penelitian adalah penelitian analitik observasional dengan desain kasus kontrol.

\section{Populasi dan Sampel Penelitian}

Populasi dalam penelitian ini adalah seluruh ibu bersalinan di Kota Tarakan. Penelitian dilakukan di RSUD Tarakan, Kalimantan Utara tahun 2020. Pengambilan sampel dengan menggunakan teknik purposive sampling. Subjek yang digunakan sebanyak 250 subjek penelitian.

\section{Variabel Penelitian}

Variabel dependen dalam penelitian ini adalah persalinan seksio sesaria dan 
variabel independen adalah umur, paritas, riwayat penyakit, faktor risiko, indikasi medis dan gambaran ANC.

\section{Teknik Pengolahan dan Analisis Data}

Analisis faktor-faktor yang mempengaruhi persalinan seksio sesaria dengan uji statistik regresi logistik dengan menggunakan SPSS 17 for window.

\section{HASIL DAN PEMBAHASAN}

Tabel 1. Distribusi Frekuensi Umur, Paritas, Riwayat Penyakit, Faktor Risiko, Indikasi Medis dan Gambaran ANC

\begin{tabular}{|c|c|c|}
\hline Karakteristik & $\mathbf{n}$ & $(\%)$ \\
\hline \multicolumn{3}{|l|}{ Umur } \\
\hline 20 tahun -35 tahun & 106 & 42.4 \\
\hline$<20$ dan $\geq 35$ tahun & 144 & 57.6 \\
\hline \multicolumn{3}{|l|}{ Paritas } \\
\hline Primipara & 126 & 50.4 \\
\hline Multipara & 124 & 49.6 \\
\hline \multicolumn{3}{|l|}{ Riwayat Penyakit } \\
\hline Tidak Memiliki & 123 & 49.2 \\
\hline Memiliki & 127 & 50.8 \\
\hline \multicolumn{3}{|l|}{ Faktor Risiko } \\
\hline Tidak Memiliki & 124 & 49.6 \\
\hline Memiliki & 126 & 50.4 \\
\hline \multicolumn{3}{|l|}{ Indikasi Medis } \\
\hline Tidak Ada & 106 & 42.4 \\
\hline Ada & 144 & 57.6 \\
\hline \multicolumn{3}{|l|}{ Gambaran ANC } \\
\hline Tidak Lengkap & 119 & 47.6 \\
\hline Lengkap & 131 & 52.4 \\
\hline
\end{tabular}

Sumber: Data Sekunder

Distribusi frekuensi karakteristik subjek penelitian menunjukkan sebagian besar dari subjek penelitian dengan umur $<20$ dan $\geq 35$ tahun yaitu sebanyak 144 $(57.6 \%)$, paritas ibu adalah primipara yaitu sebanyak subjek 126 (50.4\%), ibu bersalin yang memiliki riwayat penyakit yaitu sebanyak $127(50.8 \%)$, memiliki faktor risiko yaitu sebanyak subjek 126 $(50.4 \%)$, ada indikasi medis yaitu sebanyak 144 (57.6\%). Karakteristik yang terakhir adalah gambaran ANC, sebagian besar dengan gambaran ANC yang lengkap yaitu sebanyak 131 $(52.4 \%)$.

Tabel 2. Analisis Bivariat

\begin{tabular}{|c|c|c|c|c|c|c|c|c|}
\hline \multirow{3}{*}{$\begin{array}{l}\text { Kelompok } \\
\text { Variabel }\end{array}$} & \multicolumn{4}{|c|}{$\begin{array}{r}\text { Persalinan Seksio } \\
\text { Sesaria }\end{array}$} & \multirow{2}{*}{\multicolumn{2}{|c|}{ Total }} & \multirow{3}{*}{ OR } & \multirow{3}{*}{$\mathbf{p}$} \\
\hline & \multicolumn{2}{|c|}{ Tidak } & \multicolumn{2}{|c|}{ Ya } & & & & \\
\hline & $\mathbf{N}$ & $\%$ & $\mathbf{N}$ & $\%$ & $\mathbf{N}$ & $\%$ & & \\
\hline \multicolumn{9}{|l|}{ Umur } \\
\hline $20-35$ tahun & 75 & 70.8 & 31 & 29.2 & 106 & 100 & \multirow{2}{*}{11.52} & \multirow{2}{*}{$<0.001$} \\
\hline $\begin{array}{l}<20 \text { dan } \geq 35 \text { tahun } \\
\text { Paritas }\end{array}$ & 25 & 17.4 & 119 & 82.6 & 144 & 100 & & \\
\hline Primipara & 82 & 65.1 & 44 & 34.9 & 126 & 100 & \multirow[t]{3}{*}{10.98} & \multirow[t]{3}{*}{$<0.001$} \\
\hline Multipara & 18 & 14.5 & 106 & 85.5 & 124 & 100 & & \\
\hline Riwayat Penyakit & & & & & & & & \\
\hline Tidak Memiliki & 71 & 57.7 & 52 & 42.3 & 123 & 100 & \multirow{3}{*}{2.67} & \multirow{3}{*}{$<0.001$} \\
\hline Memiliki & 29 & 22.8 & 98 & 77.2 & 127 & 100 & & \\
\hline Faktor Risiko & & & & & & & & \\
\hline Tidak Memiliki & 78 & 62.9 & 46 & 37.1 & 124 & 100 & 8.02 & $<0.001$ \\
\hline
\end{tabular}




\begin{tabular}{lcccccccc} 
Memiliki & 22 & 17.5 & 104 & 82.5 & 126 & 100 & & \\
Indikasi Medis & & & & & & & & \\
Tidak Ada & 63 & 59.4 & 43 & 40.6 & 106 & 100 & 4.24 & $<0.001$ \\
$\begin{array}{l}\text { Ada } \\
\text { Gambaran ANC }\end{array}$ & 37 & 25.7 & 107 & 74.3 & 144 & 100 & & \\
Lengkap & 23 & 19.3 & 96 & 80.7 & 119 & 100 & 0.17 & $<0.001$ \\
Tidak Lengkap & 77 & 58.8 & 54 & 41.2 & 131 & 100 & & \\
\hline
\end{tabular}

Berdasarkan Tabel 2 menunjukkan bahwa analisis hubungan antara umur dan persalinan seksio sesaria dengan nilai $\mathrm{p}<0.001$ dan $\mathrm{OR}=11.52$, sehingga dapat diinterpretasikan bahwa ada hubungan yang signifikan. Ibu bersalin < 20 dan $\geq 35$ tahun memiliki kemungkinan 11.52 kali untuk melakukan persalinan seksio sesaria dibandingkan dengan ibu bersalin dengan umur 20 dan 35 tahun. Analisis hubungan antara paritas dan persalinan seksio sesaria dengan nilai $p<$ 0.001 dan $\mathrm{OR}=10.98$, sehingga dapat diinterpretasikan bahwa ada hubungan yang signifikan. Ibu bersalin yang mempunyai paritas multipara memiliki kemungkinan 10.98 kali untuk menggunakan persalinan seksio sesaria dibandingkan dengan ibu bersalin dengan paritas primipara. Analisis hubungan antara riwayat penyakit dan persalinan seksio sesaria dengan nilai $\mathrm{p}<0.001$ dan $\mathrm{OR}=2.67$, sehingga dapat diinterpretasikan bahwa ada hubungan yang signifikan. Ibu bersalin yang memiliki riwayat penyakit memiliki kemungkinan 2.67 kali untuk menggunakan persalinan seksio sesaria dibandingkan dengan ibu bersalin yang tidak memiliki riwayat penyakit. Analisis hubungan antara faktor risiko dan persalinan seksio sesaria dengan nilai $p$
$<0.001$ dan $\mathrm{OR}=8.02$, sehingga dapat diinterpretasikan bahwa ada hubungan yang signifikan. Ibu bersalin yang memiliki faktor risiko memiliki kemungkinan 8.02 kali untuk menggunakan persalinan seksio sesaria dibandingkan dengan ibu bersalin yang tidak memiliki faktor risiko. Analisis hubungan antara indikasi medis dan persalinan seksio sesaria dengan nilai $p$ $<0.001$ dan $\mathrm{OR}=4.24$, sehingga dapat diinterpretasikan bahwa ada hubungan yang signifikan. Ibu bersalin dengan indikasi medis memiliki kemungkinan 4.24 kali untuk mempunyai persalinan seksio sesaria dibandingkan dengan ibu bersalin yang tidak ada indiaksi medis. Analisis hubungan antara gambaran ANC dan persalinan seksio sesaria dengan nilai $\mathrm{p}<0.001$ dan $\mathrm{OR}=0.17$, sehingga dapat diinterpretasikan bahwa ada hubungan yang signifikan. Ibu bersalin yang mempunyai gambaran ANC lengkap memiliki kemungkinan 0.17 kali untuk menggunakan persalinan seksio sesaria dibandingkan dengan ibu bersalinan yang mempunyai gambaran ANC tidak lengkap.

\section{Analisis Multivariat}

Pada analisis multivariat ini dapat dilihat pada tabel dibawah ini:

\section{Tabel 3. Analisis Faktor - Faktor yang Mempengaruhi Persalinan Seksio} Sesaria

\begin{tabular}{lcccc}
\hline \multirow{2}{*}{ Persalinan Seksio Sesaria } & OR & \multicolumn{2}{c}{ CI 95\% } & Batas \\
\cline { 3 - 4 } & & $\begin{array}{c}\text { Batas } \\
\text { Atas }\end{array}$ & P \\
\hline Umur & 1.78 & 2.53 & 13.79 & $<0.001$ \\
Paritas & 1.81 & 2.36 & 15.94 & $<0.001$ \\
Riwayat penyakit & 1.61 & 2.04 & 12.17 & $<0.001$ \\
Faktor risiko & 1.36 & 1.53 & 9.92 & 0.004 \\
Indikasi medis & 2.04 & 3.09 & 19.19 & $<0.001$ \\
Gambaran ANC & -1.89 & 2.76 & 15.50 & $<0.001$ \\
\hline
\end{tabular}

Hasil analisis multivariat menunjukkan ada hubungan umur dengan persalinan seksio sesaria. Ibu dengan umur $<20$ dan $\geq 35$ tahun memiliki kemungkinan untuk menggunakan persalinan seksio sesaria $\quad(\mathrm{OR}=1.78 ; 95 \% \quad \mathrm{CI}=2.53 \quad$ - 
13.79; $\mathrm{p}<0.001)$. Hubungan paritas dengan persalinan seksio sesaria. Ibu bersalin dengan paritas yang multipara memiliki kemungkinan untuk menggunakan persalinan seksio sesaria $(\mathrm{OR}=1.81 ; 95 \% \mathrm{CI}=2.36$ - 15.94; $\mathrm{p}<0.001)$. Hubungan riwayat penyakit dengan persalinan seksio sesaria. Ibu dengan riwayat penyakit memiliki kemungkinan untuk menggunakan persalinan seksio sesaria $(O R=1.61$; $95 \% \quad C I=2.04 \quad-12.17 ; \quad p<0.001)$. Hubungan faktor risiko dengan persalinan seksio sesaria. Ibu dengan dengan faktor risiko memiliki kemungkinan untuk menggunakan persalinan seksio sesaria $(\mathrm{OR}=1.36 ; 95 \% \mathrm{CI}=1.53-9.92 ; \mathrm{p}=$ $0.004)$. Hubungan indikasi medis dengan persalinan seksio sesaria. Ibu dengan dengan indikasi medis memiliki kemungkinan untuk menggunakan persalinan seksio sesaria $(\mathrm{OR}=2.04$; $95 \% \quad C I=3.09-19.19 ; \quad p<0.001)$. Hubungan gambaran ANC dengan persalinan seksio sesaria. Ibu dengan dengan gambaran ANC yang lengkap memiliki kemungkinan untuk menggunakan persalinan seksio sesaria $(\mathrm{OR}=-1.89 ; 95 \% \mathrm{CI}=2.76-15.50$; $\mathrm{p}<0.001)$.

\section{Hubungan umur dengan persalinan seksio sesaria}

Hasil penelitian menunjukan terdapat hubungan umur dengan persalinan seksio sesaria. Mylonas dan Friese (2015) menjelaskan bahwa adanya peningkatan usia rata-rata kehamilan menjadi peran substansial yang berhubungan dengan peningkatan kejadian persalinan seksio sesaria. Kehamilan pada wanita berusia di atas 35 tahun telah merupakan kehamilan berisiko tinggi. Seiring bertambahnya usia ibu menyebabkan ibu hamil memiliki risiko malformasi bawaan janin, hipertensi atau bahkan diabetes mellitus. Umur bukan merupakan indikasi untuk persalinan seksio sesaria, namun berkaitan dengan terjadinya risiko spesifik pada kelompok usia ini yang dapat menyebabkan indikasi untuk persalinan seksio sesaria pada umur di bawah 20 tahun karena organ-organ reproduksi belum sempurna secara keseluruhan dan perkembangan kejiwaan belum matang sehingga belum siap menjadi ibu dan menerima kehamilannya.

Khalil et al. (2013) berdasarkan hasil penelitian menunjukkan bahwa umur yang $\geq 40$ tahun memiliki kemungkinan 1.95 kali untuk terjadinya persalinan seksio sesaria dibandingkan dengan ibu bersalinan yang berumur $<40$ tahun. Ibu hamil dengan umur $\geq 40$ tahun memiliki risiko terjadinya komplikasi kehamilan seperti persalinan yang tidak maju, persalinan lama, plasenta previa, solusio plasenta, disproporsi sefalopelvik, faktor janin dan jalan lahir. Sihombing et al. (2017) juga menjelaskan bahwa peningkatan umur ibu hamil berhubungan positif dengan peningkatan risiko persalinan seksio sesaria.

\section{Hubungan paritas dengan persalinan seksio sesaria}

Hasil penelitian menunjukan terdapat hubungan paritas dengan persalinan seksio sesaria. Benzouina et al. (2016) menjelaskan bahwa paritas adalah jumlah kelahiran anak dari kehamilan sebelumnya dengan janin hidup atau mati baik melalui persalinan normal ataupun persalinan seksio sesaria. Morbiditas janin masih tinggi pada persalinan seksio sesaria dibandingkan dengan persalinan normal karena komplikasi lebih sering terjadi pada persalinan seksio sesaria terutama karena paritas yang tinggi.

Timofeev et al. (2013) menjelaskan bahwa salah satu faktor yang berhubungan dengan persalinan seksio sesaria adalah paritas yang multipara. Paritas yang multipara mengalami penurunan fungsi reproduksi, otot uterus terlalu regang dan kurang dapat berkontraksi dengan baik sehingga kemungkinan persalinan seksio sesaria menjadi lebih besar.

Persalinan seksio sesaria elektif adalah salah satu faktor utama yang berkontribusi pada peningkatan pengiriman persalinan seksio sesaria primer pada wanita primipara dan multipara dengan persentase yang terbesar adalah multipara (Kawakita et al. (2016). Sejalan dengan hal tersebut Padlilah dan Yulianti (2020) juga 
menjelaskan bahwa persalinan seksio sesaria secara elektif biasanya dilakukan dalam kondisi terkontrol dan lebih siap, sehingga tingkat kecenderungan komplikasi akan lebih rendah daripada dalam situasi darurat.

\section{Hubungan riwayat penyakit dengan persalinan seksio sesaria} Hasil penelitian menunjukan terdapat hubungan riwayat penyakit dengan persalinan seksio sesaria. Abebe et al. (2016) menjelaskan bahwa persalinan seksio sesaria adalah salah satu upaya untuk penanganan masalah pada kehamilan yang dilakukan untuk melahirkan bayi, karena penanganan terbaik apabila ada masalah pada kehamilan yang memiliki riwayat penyakit salah satunya dengan dilahirkan melalui persalinan seksio sesaria untuk menurunkan risiko mortalitas ibu dan janin.

Riwayat penyakit berhubungan positif dengan persalinan seksio sesaria. Diabetus mellitus, anemia, hipertensi dan pre eklampsia merupakan peyakit yang biasanya menyertai kehamilan sehingga menyebabkan ibu harus melakukan persalinan seksio sesaria sebagai alternatif pilihan untuk intervensi persalinan (Mascarello, Horta and Silveira, (2017). Balla et al. (2018) menunjukkan hasil penelitian yang berbeda yaitu adanya riwayat penyakit atau komorbiditas tidak berhubungan dengan persalinan seksio sesaria, sehingga dibutuhkan penelitian yang relevan untuk mengkaji hubungan riwayat penyakit dengan persalinan seksio sesaria.

\section{Hubungan faktor risiko dengan persalinan seksio sesaria}

Hasil penelitian menunjukan terdapat hubungan faktor risiko dengan persalinan seksio sesaria. Obesitas adalah salah satu faktor risiko yang diketahui untuk persalinan seksio sesaria. Identifikasi faktor-faktor risiko yang mengarah pada peningkatan risiko persalinan seksio sesaria penting untuk dikaji, untuk mengidentifikasi peluang untuk mengurangi persalinan seksio sesaria primer. Peningkatan BMI dikaitkan dengan peningkatan risiko untuk pengiriman persalinan seksio sesaria karena wanita obesitas juga memiliki risiko komplikasi pasca operasi yang lebih tinggi termasuk endometritis, infeksi luka oprasi dan tromboembolisme. Persentase pengiriman persalinan seksio sesaria primer untuk makrosomia meningkat dengan peningkatan kelas BMI (Body Massa Indeks) dan tidak dipengaruhi faktor dari paritas (Kawakita et al., 2016). Dolf et al. (2018) juga menjelaskan bahwa indikasi medis menyebabkan ibu bersalin dengan persalinan seksio sesaria salah satunya dengan indikasi makrisomia. Berdasarkan hasil penelitian menunjukkan bahwa meningkatnya prosentase persalinan seksio sesaria berhubungan dengan obesitas dan riwayat penyakit seperti hipertensi.

\section{Hubungan indikasi medis dengan persalinan seksio sesaria}

Hasil penelitian menunjukan terdapat hubungan indikasi medis dengan persalinan seksio sesaria. Mylonas dan Friese (2015) menjelaskan bahwa indikasi medis berhubungan kuat dengan risiko persalinan seksio sesaria. Obesitas dan diabetes melitus yang terjadi sebelum ibu hamil meningkatkan kemungkinan ibu bersalin melakukan persalinan seksio sesaria. Diabetes melitus atau diabetes kehamilan jika tidak diobati dapat mengakibatkan kelahiran anak dengan berat lahir lebih dari 4000 gram. Obesitas dikaitkan dengan risiko lain seperti hipertensi, selain itu terjadinya makrosomia janin dianggap sebagai indikasi medis untuk dilakukan persalinan seksio sesaria.

Charvalho et al. (2019) berdasarkan hasil penelitian menunjukkan bahwa indikasi yang paling umum persalinan seksio sesaria adalah bekas luka rahim sebelumnya (riwayat persalinan seksio sesar sebelumnya) porsentasenya meningkat dari 1,2 menjadi $2,3 \%(p<$ $0,001)$. Indikasi kedua yang paling umum adalah asfiksia janin yang harus segera ditangani dengan persentase meningkat dari 2,4 menjadi $2,6 \%(p<0,01)$, selain itu persalinan lama, komplikasi 
kehamilan dan rupture uteri juga menjadi indikasi persalinan seksio sesaria.

\section{Hubungan gambaran ANC dengan persalinan seksio sesaria}

Hasil penelitian menunjukan terdapat hubungan gambaran ANC dengan persalinan seksio sesaria. Karim et al. (2019) menjelaskan bahwa gambaran ANC adalah salah satu faktor yang berhubungan dengan persalinan seksio sesaria. Gambaran ANC yang lengkap dapat digunakan sebagai upaya untuk deteksi dini baik petugas kesehatan dan ibu hamil untuk memamtau kondisi ibu dan janin terkait kesehatan, kemungkinan komplikasi yang terjadi selama kehamilan, selain itu tenaga kerja dan jenis fasilitas tempat persalinan berhubungan dengan persalinan seksio sesaria.

Ibu hamil yang melakukan kunjungan ANC lengkap memiliki kemungkinan untuk mengakses pelayanan kesehatan sehingga informasi terkait persalinan lebih banyak dibandingkan dengan ibu yang gambaran ANC tidak lengkap. Minimal empat kali kunjungan ANC harus dilakukan sehingga penyediaan layanan perawatan antenatal dan postnatal harus memenuhi standar pelayanan kebidanan. ANC yang berkualitas serta konseling selama kehamilan dapat menurunkan kemungkinan komplikasi pada kehamilan sekaligus sebagai upaya deteksi dini persalinan faktor risiko persalinan seksio sesaria (Rahman et al., 2018).

Begum et al. (2017), gambaran ANC ibu hamil yang lengkap adalah variabel penting yang berpengaruh terhadap persalinan seksio sesaria. Hasil pemeriksaan ANC juga dapat digunakan sebagai data penungjang untuk melaksanakan rujukan pasien. Mayoritas ibu hamil rata-rata $76 \%$ setidaknya tiga kunjungan antenatal (ANC) dan 19\% memiliki riwayat kebidanan yang buruk. Usia, paritas, pendidikan tinggi, status sosial ekonomi, riwayat kebidanan dan gambaran ANC merupakan faktor yang erat kaitannya dan secara statistik signifikan berhubungan dengan persalinan seksio sesaria. WHO menjelaskan bahwa kunjungan ANC yang lengkap sangat direkomendasikan karena merupakan faktor penting untuk mendeteksi anomali janin bawaan yang bertanggung jawab atas terjadinya oligo hidrasi dan juga untuk mengidentifikasi potensi ancaman atau komplikasi pada janin secara dini. Kualitas ANC yang buruk sebagian besar karena kurangnya infrastruktur fisik, lebih banyak waktu tunggu, perilaku yang kurang mendukung dari penyedia layanan dan kurangnya Prosedur Operasi Standar (SOP) dan kurangnya praktik berbasis bukti seperti konseling serta pendidikan kesehatan.

\section{KESIMPULAN}

Persalinan seksio sesaria dipengaruhi oleh umur $<20$ dan $\geq 35$ tahun, paritas yang multipara, memiliki riwayat penyakit, memiliki faktor risiko, ada indikasi medis dan gambaran ANC yang lengkap.

\section{DAFTAR PUSTAKA}

Balla JDE, Paun R, Ludji IDR. 2018: Factors related to healing process of sectio caesarea surgical wound. Unnes Journal of Public Health 7 (2).

Begum $T$, Rahman A, Nababan $\mathrm{H}$, Hoque DME, Khan AF, Ali T, et al. 2017: Indications and determinants of caesarean section delivery: evidence from a population-based study in Matlab, Bangladesh. PLoS ONE 12(11): e0188074.

Benzouina S, Boubkraoui MEM, Mrabet M, Chahid N, Kharbach A, El-Hassani $A$, et al. 2018: Fetal outcome in emergency versus elective cesarean sections at Souissi Maternity Hospital, Rabat, Morocco. Pan Afr Med J 23:197.

Charvalho PS, Bittár MH, Stjernholm YV. 2016. Indications for increase in caesarean delivery. Reproductive Health 16:72

de Oliveira RR, Melo EC, Novaes ES, Ferracioli PLRV, Mathias TA de F. 2016. Factors associated to caesarean delivery in public and private health care systems. Rev da Esc Enferm 50(5):733-40.

Dolf G, Gaillard C, Russenberger J, Moseley L, Schelling C. 2018. 
JURNAL BORNEO SAINTEK

Volume 4, Nomor 1, April 2021

e-ISSN 2599-3313

P-ISSN 2615-434X

Factors contributing to the decision to perform a cesarean section in Labrador retrievers. BMC Veterinary Research 14:57

Keag OE, Norman JE, Stock SJ. 2018: Long-term risks and benefits associated with cesarean delivery for mother, baby, and subsequent pregnancies: Systematic review and meta-analysis. PLoS Med 15(1):1-22.

Hasan MM, Hoque DM.E, et al. 2020: Prevalence and factors associated with caesarean section in four Hard-to-Reach areas of
Available online at www.jurnal.borneo.ac.id Halaman 23-30

Bangladesh: Findings from a cross-sectional survey. PLOS ONE 15(6): e0234249.

Khalil A, Syngelaki A, Maiz N, Zinevich Y, Nicolaides $\mathrm{KH}$. 2013: Maternal age and adverse $p$ regnancy outcome: a cohort stud y. Ultrasound in Obstetrics \& Gynecology 42(6): 634-643.

Knight $M$, Tuffnell $D$, Kenyon $S$, Shakespeare J, Gray R, Kurinczuk J. 2015: MBRRACE-UK: Saving lives, improving mothers' care. surveillance of maternal 